1. MBBS, MCPS, M.SC (Critical Care) Consultant

Department of Anesthetist

District Head Quarter Hospital, Faisalabad.

2. MBBS, DRCOG

Postgraduate Trainee in General Practice

East Lancashire Hospitals NHS Trust,

Burnley General Hospital,

Casterton Avenue, Burnley,

United Kingdom, BB10 2PQ

3. FRCP (Edin), FRCP (Glasg),

FRCR (Clinical Oncology)

Consultant Medical Oncologist

Department of Oncologist

King Fahad Specialist Hospital,

Dammam, 31444, Kingdom of Saudi

Arabia.

4. FCPS (Gyne \& Obs)

Associate Professor

Department of Gynaecology \& Obstetrics

Unit 3, Allied Hospital, Faisalabad.

5. PhD. Statistics

Professor and Head

Department of Statistics

Samanabad Science College, Faisalabad.

6. Postgraduate Trainee

Department of Orthopedics

Allied hospital, Faisalabad.

7. Postgraduate Trainee in Internal Medicine, Faisalabad Institute of Cardiology,

Faisalabad.

Correspondence Address:

Dr. Sajida Iftikhar

Department of Anesthetist

District Head Quarter Hospital,

Faisalabad.

dr.sajidaiftikhar@gmail.com

Article received on:

03/05/2018

Accepted for publication:

$19 / 12 / 2018$

Received after proof reading:

$28 / 08 / 2019$

\section{VENOUS THROMBOEMBOLISM AN OBSERVATIONAL STUDY TO ASSESS THE RISK OF VENOUS THROMBOEMBOLISM IN SURGICAL PATIENTS.}

\begin{abstract}
Sajida Iftikhar ${ }^{1}$, Ayesha Farooq ${ }^{2}$, Muhammad Farooq Latif ${ }^{3}$, Sarwat Ara ${ }^{4}$, Muhammad Salim ${ }^{5}$,
\end{abstract} Asif Maqbool $^{6}$, Aatar ${ }^{7}$

ABSTRACT... Objectives: The aim of this study is to assess the risk of venous thromboembolism (VTE) in surgical patients. Study Design: An Observational Study. Setting: 4 Tertiary Hospitals in Faisalabad city. Period: 6 months from July 2015 to December 2015. Material \& Methods: Clinical data sheets of surgical in patients of 4 teaching hospitals in Faisalabad city were retrospectively reviewed. Caprini assessment model (CAM) was used for VTE risk assessment and the patients were classified into very high risk (VHR), high risk (HR), moderate risk (MR) and low risk (LR) groups. The data was collected on an Excel spread sheet and statistical analysis was done using SPSS version 17. Chi square test was carried out to assess the association of VTE risk with age, gender, BMI and surgical units. Results: We identified a total of 256 patients from July 2015 to December 2015. The median age was 42 years. 118 (46\%) patients were male and 138 (54\%) were female. 106 (41.4\%) patients were VHR and 124 (48.4\%) patients were HR for VTE according to CAM. Nineteen (7.4\%) patients were MR and only $7(2.7 \%)$ patients were LR. Higher age and male gender were found to be significantly associated with the high risk for VTE $(p<0.001)$. Conclusion: Our study shows that the postoperative surgical patients are at higher risk of developing VTE. There is statistically significant association between increasing age and male gender with risk of VTE in this group of patients.

Key words: $\quad$ Venous Thromboembolism, VTE.

Article Citation: Iftikhar S, Farooq A, Latif MF, Ara S, Salim M, Maqbool A, Aatar. Venous thromboembolism; an observational study to assess the risk of venous thromboembolism in surgical patients. Professional Med J 2019; 26(9):1531-1536. DOI: 10.29309/TPMJ/2019.26.09.4018

\section{INTRODUCTION}

Venous thromboembolism (VTE) comprises of Deep vein thrombosis (DVT) and pulmonary embolism (PE). DVT refers to formation of blood clots in one of the body's large veins, most commonly in the lower limbs. Proximal DVT is defined as DVT in iliac, femoral or popliteal veins while Distal DVT refers to thrombosis distal to the popliteal veins including calf muscle veins. PE occurs when a portion of blood clot breaks loose and travels in the blood stream, first to heart and then to lungs causing partial or complete blockage of pulmonary artery or one of its branches. ${ }^{1}$ The phenomenon of VTE compromises venous return of blood flow from the affected area. In the specific case of PE, VTE can result in decreased oxygenation of the blood by the lungs. VTE is a cardiovascular disease and risk factors for arterial and venous thrombosis (VT) are the same. The
Virchow's Triad proposes that VTE occurs as a result of blood stasis, vascular endothelial injury and inherited or acquired hypercoaguable states. ${ }^{2}$ Keeping in view the pathophysiology of VTE, the patients after surgery are at higher risk of VTE because surgery induces inflammatory responses and hypercoagulable state along with endothelial injury. After surgery limited movements result in venous stasis. If other risk factors are also present, the patient may be at high risk of VTE. ${ }^{3}$

Postoperative PE and DVT are major causes of mortality and morbidity in surgical patients. ${ }^{4}$ Over one hundred and fifty thousand deaths occur annually in United States due to VTE. The death rate from $P E$ exceeds the death rate of myocardial infarction (MI), and $80 \%$ of patients who died of $\mathrm{PE}$ are diagnosed on postmortem examination. ${ }^{5}$ 
It is thought that the incidence of VTE is lower in the Asian population as compared to Western countries but this is not true. ${ }^{6}$ Wong etal concluded that incidence of symptomatic VTE in Asian trauma patients is the same as in American population. ${ }^{7}$ According to $\mathrm{S}$. Liao et al, the incidence of VTE is lower in Asian than Europeans; however the proportion of provoked and preventable events are similar to those of European population. ${ }^{8}$ Cohen et al reported similar results of VTE events after major orthopedic surgery. In a systematic review and meta-analysis by B. Kanchanabat et al, there was no postoperative death despite omission of thromboprophylaxis after 2000 orthopedic procedures. ${ }^{9}$ This review does not represent population of south Asian countries which include a substantial proportion of Asia representing nearly $20 \%$ of the world's population. Another systematic review and meta-analysis by B.Kanchanabat et al reported that rate and mortality of post-operative VTE in moderate risk surgery in Asian patients is less than European and American population. ${ }^{10}$ This study also does not include South Asian population and venogram for diagnosis of DVT was done only in one study. Susanto A.P et al concluded after a cross-sectional study in Singapore that incidence of VTE after major surgery is as common in Asian patients as published data in other populations. ${ }^{11}$ Sixty percent of the patients with fatal outcome have some prodromal symptoms which are often misinterpreted and preventive treatment is not provided..$^{12}$ Eighty percent of deaths due to VTE are diagnosed after postmortem examination. ${ }^{13}$ This observational study was conducted across 4 teaching hospitals in Faisalabad city to estimate the risk of VTE in surgical patients.

\section{MATERIALS AND METHODS}

We retrospectively reviewed clinical case notes of patients admitted to surgical units of 4 teaching institutions in Faisalabad city including Punjab medical college, Madinah medical college, Independent Medical College and Aziz Fatima Medical College from July 2015 to December 2015. Three of these institutions were in private sector and all four hospitals had over 100 acute care beds and performed major surgical procedures. Data was collected from general surgical, orthopedics, neurosurgery and Gynecology \& obstetrics (G\&O) units allowing inclusion of all patients with age over 18years, immobility for more than 72 hours due to any surgical procedure or complication of surgery or surgical procedure lasting more than 45 minutes duration under general, spinal or epidural anesthesia. General medical, pediatric, cardiac surgical and palliative care patients were excluded from the study as well as the patients with incomplete medical records. A team of 4 doctors collected the data after formal training about the study aim, design and ethical protocols. The data was collected on data forms and Caprini Risk Assessment Model was selected for this purpose. The data included patient age, gender, weight, blood group, name of surgical unit and surgical procedure performed. The risk factors for each patient were scored and added up to obtain the cumulative VTE risk and level of risk. The risk score and stratification of patient into low risk (LR), moderate risk (MR), high risk (HR) or very high risk (VHR) was performed according to Caprini risk assessment model. Based on BMI, patients were further categorized into 2 groups (BMl $>30$, $\mathrm{BMl}<30$ ). The sample size for $95 \%$ confidence interval $(\mathrm{Cl})$ and error of $5 \%$ was calculated to be 256. The study was approved by Ethical Review Committee of Pakistan Medical Research Council. This was a retrospective observational study hence the patient's consent was waived off. The medical records of 256 patients were reviewed. Incomplete data forms were not included in final analysis. A descriptive analysis of the percentage of the study population with level of risk was calculated. All data was collected on an Excel spread sheet and statistical analysis was done using SPSS version 17. Chi square test was carried out to assess the association of VTE risk with age, gender, BMI and surgical units.

\section{RESULTS}

A total of 256 patients were identified from 4 hospitals in Faisalabad city in the period from July 2015 to December 2015 with a median age of 42 years. Eleven percent of patients were above the age of 61 years. Forty six $(n=118)$ percent of patients were males and fifty four $(n=138)$ percent were females. After exclusion of G\&O patients, there were $65.2 \%(n=118)$ males 
and $34.8 \%(n=63)$ females in general surgery, orthopedic surgery, and neurosurgery. The study population contained 90 (35.2\%) patients from general surgical units followed by G\&O $(n=75$, $29.3 \%)$, Orthopedic surgery $(n=56,21.8 \%)$ and neurosurgery $(n=35,13.7 \%)$ respectively. Table-I

Twenty six (10\%) patients were obese with $\mathrm{BMI}>30 \%$. Identified risk factors for VTE included malignancy $(n=10,4 \%)$, myocardial infarction, heart failure or chest infection $(n=16$, $6.25 \%$ ), hormone replacement therapy or oral contraceptive pills $(n=4,1.56 \%)$, multiple trauma $(n=22,8.6 \%)$, hip or knee surgery $(n=25,9.76 \%)$, stroke due to trauma or as a complication of surgery $(n=17,6.64 \%)$, inflammatory bowel disease $(n=1,0.39 \%)$ and varicose veins $(n=2$, $0.78 \%)$ respectively.

Using caprini risk assessment model, 106 (41.4\%) patients were identified as VHR for VTE followed by HR $(n=124,48.4 \%)$, MR $(n=19,7.4 \%)$ and LR $(n=7,2.7 \%)$.

\begin{tabular}{|l|c|c|c|c|c|}
\hline Surgical Specialty & Number & Males & Females & Median Age & BMI> $30 \%$ \\
\hline General Surgery & 90 & 54 & 36 & 45 years & 11 \\
\hline Orthopedic Surgery & 56 & 37 & 19 & 43 & 4 \\
\hline Neurosurgery & 35 & 27 & 8 & 40 & 4 \\
\hline Obs \& Gynae & 75 & NA & 75 & 40 & 5 \\
\hline
\end{tabular}

Table-I. Patient demographics in different surgical specialties

\begin{tabular}{|l|c|c|c|c|}
\hline Surgical Specialty & $\begin{array}{c}\text { Very High Risk } \\
\text { (VHR) }\end{array}$ & $\begin{array}{c}\text { High Risk } \\
\text { (HR) }\end{array}$ & Moderate Risk (MR) & $\begin{array}{c}\text { Low Risk } \\
\text { (LR) }\end{array}$ \\
\hline General Surgery & $45.6 \%, n=41$ & $50 \%, n=45$ & $3.3 \%, n=3$ & $1.1 \%, n=1$ \\
\hline Orthopedic Surgery & $69.6 \%, n=39$ & $16.1 \%, n=9$ & $12.5 \%, n=7$ & $1.8 \%, n=1$ \\
\hline Neurosurgery & $54.3 \%, n=19$ & $28.6 \%, n=10$ & $17.1 \%, n=6$ & 0 \\
\hline Obs \& Gynae & $9.3 \%, n=7$ & $80 \%, n=60$ & $4 \%, n=3$ & $6.7 \%, n=5$ \\
\hline
\end{tabular}

Table-II. VTE risk stratification according to Caprini assessment model in different surgical specialties

\begin{tabular}{|l|l|l|l|l|l|l|l|l|l|l|}
\hline & & & & & & & & & & \\
\end{tabular}

Table-III. Age cross tabulation

Study of Association between Risk and Age Count 


\begin{tabular}{|l|c|c|c|}
\hline & Value & df & Asymp. Sig. (2-sided) \\
\hline Pearson Chi-Square & $49.084^{\mathrm{a}}$ & 15 & .000 \\
\hline Likelihood Ratio & 53.781 & 15 & .000 \\
\hline Linear-by-Linear Association & 34.908 & 1 & .000 \\
\hline N of Valid Cases & 256 & &
\end{tabular}

Table-IV. Chi-square tests

a. 14 cells $(58.3 \%)$ have expected count less than 5 . The minimum expected count is .25 .

\begin{tabular}{|l|c|c|c|c|}
\hline & & \multicolumn{2}{c|}{ Total } \\
\hline & & Male & Female & \\
\hline \multirow{2}{*}{ Risk } & 1 & 3 & 6 & 9 \\
\hline & 2 & 8 & 8 & 16 \\
\hline & 3 & 40 & 86 & 126 \\
\hline Total & 4 & 66 & 39 & 105 \\
\hline
\end{tabular}

Table-V. Gender cross tabulation

Study of association between risk and gender Count

\begin{tabular}{|l|c|c|c|}
\hline & Value & df & Asymp. Sig. (2- sided) \\
\hline Pearson Chi-Square & 23.016 & 3 & .000 \\
\hline Likelihood Ratio & 23.336 & 3 & .000 \\
\hline Linear-by-Linear Association & 11.174 & 1 & .001 \\
\hline N of Valid Cases & 256 & & \\
\hline
\end{tabular}

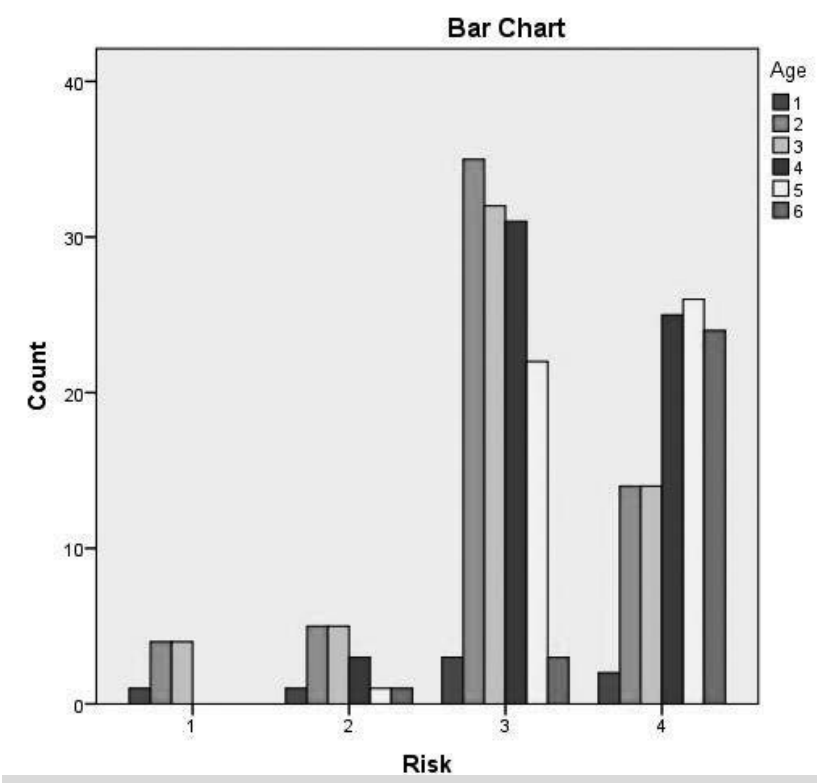

Figure-1. Age is significantly associated with Risk

$(P<0.001)$

\section{DISCUSSION}

Postoperative hospitalized surgical patients are at higher risk of VTE due to stasis, vascular endothelial injury and hypercoagulable state. There are various national and international evidence based guidelines for diagnosis and management of these patients. Caprinin risk

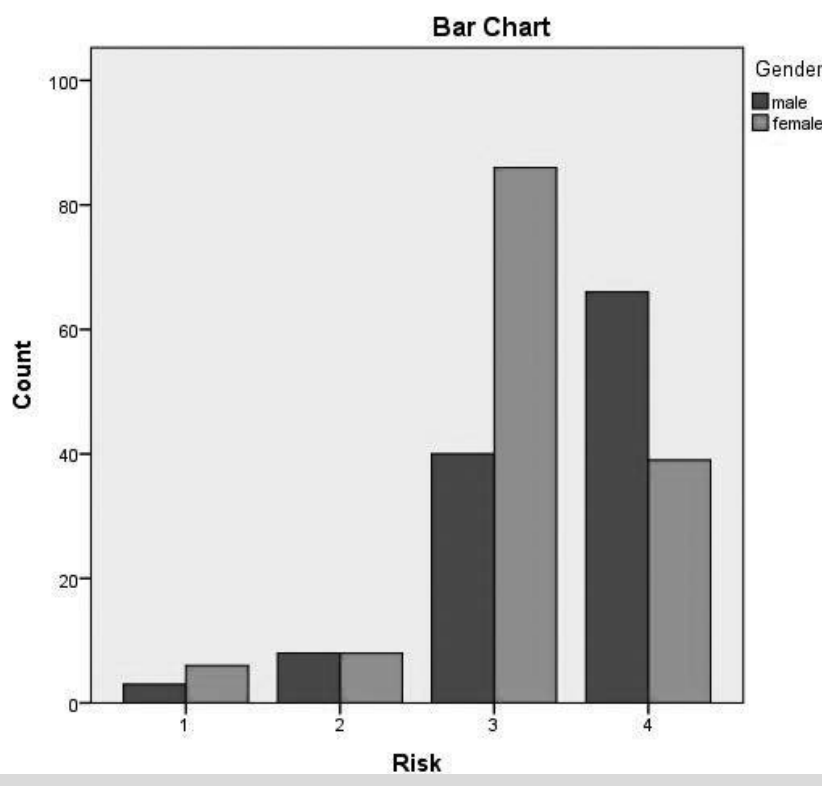

Figure-2. Gender is significantly associated with Risk $(P<0.001)$

assessment model is useful tools to risk categorize these patients and plan for thromboprophylaxis. Adherence to clinical guidelines reduces incidence and complications of VTE. ${ }^{14}$ There is a misconception that risk of VTE in surgical patients is low in Asian countries. This study was conducted to estimate the risk of VTE in four 
large tertiary hospitals in Faisalabad city and the results were compared with studies published in literature. The results of this study show that $97.2 \%$ of hospitalized surgical patients are at risk of VTE including Very High Risk (VHR=41.4\%), High Risk $(\mathrm{HR}=48.4 \%)$ and Moderate Risk $(\mathrm{MR}=7.4 \%)$ patients. ENDORSE (Epidemiologic International Day for the Evaluation of Patients at Risk for Venous Thromboembolism in the Acute Hospital Care Setting) is a multinational cross sectional study which concluded that overall $92.5 \%$ of hospitalized patients are at risk of VTE. ${ }^{15}$ Another multinational AVAIL-ME study reported that $85 \%$ hospitalized patients are at risk of VTE in middle eastern population. ${ }^{16}$ The results of our study are comparable to the results of ENDORSE study and AVAIL-ME study regarding risk of VTE in hospitalized patients. Greets et al reported that risk of postoperative VTE is very high after major orthopedic surgery and the rate of DVT after lower limb surgery is around $40-60 \%$ without thromboprophylaxis. ${ }^{17}$ These findings correspond to the results of our study which shows that $69.6 \%$ patients in orthopedic surgery were at VHR for VTE.

In our study, risk of VTE was also very high in neurosurgical patients (54.3\%) while General surgical and G\&O patients were predominantly HR for VTE. The risk factors for VTE including obesity, use of oral contraceptive pills and hormonal replacement therapy are less common. Higher age and male gender were found to have significant association with the risk of VTE which is consistent with the published data. ${ }^{18}$ Our study is a further addition to the existing literature on this subject. The results of this observational study can also help to rectify the misconception in healthcare professionals about the level of risk of VTE in Asian population. This study however has some limitations. It is a retrospective study with small sample size and the data was collected from 4 hospitals in one city. The findings may not reflect the incidence of VTE across the whole country. However the findings do highlight the gravity of the problem and need for a wider nationwide guidelines for management of this group of patients.

\section{CONCLUSION}

Vast majority of surgical inpatients are at risk of VTE. Risk assessment for venous thromboembolism should be an essential part of initial work up and management plan for these patients. Development of local and national guidelines can help improve patient care.

\section{Copyright $@ 19$ Dec, 2018.}

\section{REFERENCES}

1. Rockville (MD). The surgeon general's call to action to prevent deep vein thrombosis and pulmonary embolism. https://www.ncbi.nlm.nih.gov/books/ NBK44178.

2. Haley M. Phillippe, Pharm D, BCPS, BCGP. Overview of venous thromboembolism. Am J Manag Care. 2017; 23:S376-S382.

3. Caprini JA. Risk assessment as a guide to thrombosis prophylaxis. Curr Opin Pulm Med. 2010; 16: 448-452.

4. Cassidy MR, Rosenkranz P, McAneny D. Reducing postoperative venous thromboembolism complications with a standardized risk-stratified prophylaxis protocol and mobilization program. $J$ Am Coll Surg. 2014 Jun; 218(6):1095-104.

5. Samuel Z, Goldhaber. Risk factors for venous thromboembolism. JACC 2010, vol.56,No.1,1-7.

6. Cohen AT, Tapson VF, Bergmann JF, et al. Venous thromboembolism risk and prophylaxis in the acute hospital care setting (ENDORSE study): Lancet. 2008; 371(9610):387-94.

7. Wong TH1, Koh MP2, Ng J2. Symptomatic venous thromboembolism in Asian major trauma patients: incidence, presentation and risk factors. Eur $\mathrm{J}$ Trauma Emerg Surg. 2013 Oct; 39(5):495-500. doi: 10.1007/s00068-013-0292-4.Epub 2013 Apr 25.

8. Liao S, Woulfe T, Hyder S, Merrimas E, Simpson D. Incidence of venous thromboembolism in different ethnic groups; A regional direct comparison study. Journal of Thrombosis and Haemostasis. 2014; vol 12, issue 2, 214-19.

9. Kanchanabat B1, Stapanavatr W, Meknavin S, Soorapanth C, Sumanasrethakul C, Kanchanasuttirak $P$. Systematic review and meta-analysis on the rate of postoperative venous thromboembolism in orthopaedic surgery in Asian patients without thromboprophylaxis. Br J Surg. 2011 Oct; 98(10):135664. doi: 10.1002/bjs.7589. Epub 2011 Jun 14. 
10. Kanchanabat B1, Stapanavatr W, Manusirivithaya $S$, Srimantayamas $S$. The rate and mortality of postoperative venous thromboembolism of moderate risk surgery in Asian patients without thrombo-prophylaxis: systematic review with metaanalysis. World J Surg. 2014 Jan; 38(1):194-202. doi: 10.1007/s00268-013-2222-3.

11. Anindya P. Susanto, Charles Krisnanda, Doreen S-Y. Tan, Hean-Ye Ong, Dedy Pratama, Rasjid Soeparwata, Incidence of venous thromboembolism among patients who underwent major surgery in a public hospital in Singapore. Med J Indones, Vol 23, No.1 February 2014.

12. Cohen AT1, Agnelli G, Anderson FA, Arcelus JI, Bergqvist D, Brecht JG, Greer IA, Heit JA, Hutchinson JL, Kakkar AK, Mottier D, Oger E, Samama MM, Spannagl M; VTE Impact Assessment Group in Europe (VITAE). Venous thromboembolism (VTE) in Europe. The number of VTE events and associated morbidity and mortality. Thromb Haemost. 2007 Oct; 98(4):756-64.

13. Dentali F1, Douketis JD, Gianni M, Lim W, Crowther MA. Meta-analysis: Anticoagulant prophylaxis to prevent symptomatic venous thromboembolism in hospitalized medical patients. Ann Intern Med. 2007 Feb 20; 146(4):278-88.

14. Klaassen Z1, Arora K2, Goldberg H3, Chandrasekar T3, Wallis CJD4, Sayyid RK3, Fleshner NE3, Finelli A3, Kutikov A5, Violette PD6, Kulkarni GS4. Extended venous thromboembolism prophylaxis after radical cystectomy: A call for adherence to current guidelines. J Urol. 2017 Nov 4. pii: S00225347(17)77817-2. doi: 10.1016/j.juro.2017.08.130.
15. Dr Alexander T Cohen, Victor F Tapson, MD, Prof JeanFrancois Bergmann, MD, Prof Samuel Z Goldhaber, MD, Prof Ajay K Kakkar, PhD, Bruno Deslandes, Wei Huang, MS, Maksim Zayaruzny, MD, Leigh Emery, Prof Frederick A Anderson Jr, PhD, Venous thromboembolism risk and prophylaxis in the acute hospital care setting (ENDORSE study): The Lancet, Volume 371, No. 9610, p387-94, 2 February 2008.

16. Ali T. Taher • Joseph Aoun - Pascale Salameh. The AVAIL ME study: A multinational survey of VTE risk and prophylaxis. J Thromb Thrombolysis (2011) 31:47-56.

17. Geerts WH1, Bergqvist D2, Pineo GF3, Heit JA4, Samama CM5, Lassen MR6, Colwell. Prevention of venous thromboembolism: American College of Chest Physicians Evidence-Based Clinical Practice Guidelines (8th Edition). CW7Chest. 2008 Jun; $133(6$ Suppl):381S-453S. doi: 10.1378/chest.08-0656.

18. Chethan Gangireddy MD, JohnR. Rectenwald MD, Gilbert R. Upchurch MD, Thomas W. Wakefield MD, ShukriKhuri MD, William G. Henderson PhD, Peter K. Henke MD. Risk factors and clinical impact of postoperative symptomatic venous thromboembolism. Journal of Vascular Surgery Volume 45, Issue 2, February 2007, Pages 335-342.e1.

\begin{tabular}{|c|c|c|c|}
\hline \multicolumn{4}{|c|}{ AUTHORSHIP AND CONTRIBUTION DECLARATION } \\
\hline Sr. \# & Author-s Full Name & Contribution to the paper & Author $=$ s Signature \\
\hline 1 & Sajida Iftikhar & $\begin{array}{l}\text { Research design, literature } \\
\text { review, discussion. }\end{array}$ & \\
\hline 2 & Ayesha Farooq & $\begin{array}{l}\text { Literature review, Introduction } \\
\text { and write up. }\end{array}$ & \\
\hline 3 & M. Farooq Latif & $\begin{array}{l}\text { Discussion, write up, critical } \\
\text { analysis and final review. }\end{array}$ & \\
\hline 4 & Sarwat Ara & Proof reading, Discussion. & \\
\hline 5 & Muhammad Salim & Statistical analysis. & \\
\hline 6 & Asif Maqbool & Data collection. & \\
\hline 7 & Aatar & Data collection. & \\
\hline
\end{tabular}

